\title{
Service Design and Operations Strategy Formulation in Multicultural Markets
}

\author{
Madeline E. Pullman \\ Information Systems and Operations Management Department, Cox School of Business, Southern \\ Methodist University, Dallas, TX 75272, USA \\ Rohit Verma \\ Department of Management, Kellstadt Graduate School of Business, DePaul University, Chicago, IL \\ 60604, USA \\ John C. Goodale \\ Department of Management, College of Business, Ball State University, Muncie, IN 47306, USA
}

Businesses that service multicultural customer segments face unique challenges in developing the appropriate service strategy. While the strategic implications of expanding services from a domestic market to an international location have been well documented, multicultural customer segments at one location is a unique problem that has largely been neglected by researchers. This paper attempts to fill this gap by presenting a conceptual framework and method for determining the extent of service product and process attribute standardization versus customization in these settings. The paper presents an approach for modeling the preferences of different cultural segments, evaluating the differences between the segments and determining the appropriate service strategy for service providers. We evaluate the effects of competitors adopting their revenue maximizing strategy both independently of each other and simultaneously while assuming the size of the market is viewed as a zero sum game. In an actual application at an international airport terminal, one food-service vendor implemented the suggested operations strategy and the result was a significant revenue gain over the previous year's sales during the same period. The method has valuable implications for managers when developing strategies for delivering a service to multicultural customer segments.

\section{Introduction}

Should Euro Disney have adapted more of its US-based policies rather than attempt to satisfy a wide variety of European preferences? Should II Bellagio, a Las Vegas luxury hotel, allocate valuable retail space to a noodle restaurant targeted towards its Asian customers or to an internationally recognizable brand like McDonalds? Why does Hilton offer a separate service 
concept, 'Wa No Kutsurogi' for Japanese customers within their existing hotels (Teare, 1993)? These questions reflect the strategic tradeoffs that service firms face when operating in multicultural markets. The choices between strategic alternatives have important implications for service design, i.e. new practices may need to be designed and developed. Previously, business researchers have focused on issues related to services and products expanding into an international location. However, we focus on the distinct concept of the multinational facility a business that must service multicultural customer segments. This area has remained underresearched particularly from a service management perspective.

Danaher (1998) suggested that the lack of research on operations strategy for multicultural services relate to the problem of tailoring a service to different customer segments. We believe that a major component of this problem is the service managers' challenge of determining both process and product attributes for a service design. Process attributes include items such as employee interactions with customers, reliability and waiting time, for example. Product attributes cover tangible items such as employee appearance, building design, cleanliness levels, variety or choices and printed materials. Depending on the service concept and strategy, one would expect that certain service attributes should be adjusted for different cultural segments, while others have universal expectations and appeal. Many times, however, these attributes are standardized, patterned after successful domestic or international operations. The aim of this paper is to suggest an approach for determining the extent of both service product and process attribute standardization versus customization in multicultural settings. Specifically, we pose the following research questions.

1. How can managers identify the service preferences of their customers who belong to different nationalities or cultural segments?

2. How can key similarities and differences between the service preferences of customer segments be quantified?

3. What possible operations and marketing strategies should service managers implement to address these preference similarities and differences?

4. And, how can managers evaluate the effect of these different operations strategies on their firm's market performance in multicultural environments?

We first discuss the previous research on service expectations and perceptions of multicultural customer segments. We then outline our conceptual framework, propositions and a method for formulating service designs and operations strategy in multicultural markets. Next, we describe how our method was applied to food-service improvements at a major US international airport. We provide the implications and recommendations for terminal management and discuss results from the implementation. Finally, we discuss the significance of our findings and draw conclusions for service design and strategy based on the study.

\section{Conceptual Background}

Heskett's (1987) strategic service vision addresses the importance of linking marketing 
and operations perspectives for service design. Specifically, service designers must determine the needs and preferences of a target market and match them with the appropriate operating strategy, design and delivery system. In this section, we review research on multicultural marketing/operations issues. We consider the following in regards to markets of different cultural segments: (a) factors that influence customers' choice, (b) customer satisfaction with service experience and (c) service operations strategies. Lastly, we recognize the differences between cultural segments of service customers and we propose a method for service operations design in a multicultural environment.

\section{Multicultural Customer Segments}

According to Clark (1990), many marketing researchers have studied national character or cultural differences. Using his definition, national character is defined as enduring personality characteristics among the populations of particular nation states. Cross-national studies are valuable in international market settings because: (1) national differences exist and can be measured and (2) these differences have significant bearing on both consumer behavior and the strategic decision-makers in firms. While marketing research has focused largely on the standardization level of marketing strategies during globalization (Martenson, 1987; Jain, 1989; Clark, 1990), littie work has addressed modifications of the service strategy for a customer group with multiple culture segments.

\section{Service Attributes and Multicultural Perspectives}

The research by Parasuraman et al. $(1985,1988)$, found that customers develop service attribute expectations from marketing messages and previous experience. To design a new or improved service, managers must determine which attributes are important to customers, whether or not the service is capable of delivering the attributes according to expectation and the customer's subsequent perception of the delivered service.

Research has shown that customers from different cultures and nationalities have different expectations from services and perceptions of the actual service delivered. Generally, expectations of tangible goods differ across national culture groups (Martenson, 1987; Jain, 1989; Clark, 1990). The same holds true for services. Donthu and Yoo (1998) studied the effects of consumers' cultural orientation on bank service expectations. They found relationships between cultural orientation and expectations of service quality dimensions of reliability, responsiveness, empathy and assurance. Lee and Ulgado (1997) discovered that customer perceptions of a fast food experience were susceptible to cultural differences between South Korean and US consumers at McDonald's restaurants in their respective countries. The US consumers preferred corporate reputations or brand names, low prices and consistent quality while Korean customers valued reliability and empathetic employees. The Korean customers had higher expectations for their McDonald's experience because of the embedded US cultural messages and relatively high prices, thus they were more likely to be disappointed with their service experience than their US counterparts. 
Mattila (1999) examined the impact of culture on customer evaluations of luxury hotels in Singapore. Comparing Asian Indian, Asian Chinese and Western customer groups, she found evidence that Western customers placed significantly higher importance on physical environment and tangibles than their Asian counterparts. While customization and personalized service were significantly more important to Asian Indians than their Western counterparts, no culture-based differences were found for personal recognition and it was perceived to have low importance in that setting. Webster (1989) found that ethnic customer segments (African American, Asians, Anglos and Hispanics) had significantly different service quality expectations for both professional and non-professional services.

\section{Service Differentiation Strategies}

If different cultural expectations and perceptions of services exist, managers need to know the implication of these differences for their service strategy. Should the service strategy emphasize or target the needs of one significant segment (in terms of revenue potential or other objectives), all segments simultaneously or different segments at different times? Service differentiation strategies fall on a continuum from 'one size fits all' to totally personalized experiences for each customer. Mathe and Perras (1994) argued for differentiating the service and its quality standards depending on the cultural differences at a location. Similarly, managers should adjust the service design according to the cultural mix at their locations.

Heskett, on the other hand, argued that total experience services should not change the service strategy or the service delivery system for multinational settings (Lovemen, 1993). If customers are unfamiliar with a service concept, its appeal must be counted on to win them over. Consequently, internationally recognizable brands such as McDonald's have successfully transferred their concept to multinational environments with minimal modifications.

Ideally, if the service firm has the ability to customize the service for each client, then this approach could address any cultural or personal preferences. According to Kolesar et al. (1998), perceived customer value is created by a service's ability to personalize service delivery or 'industrialized intimacy'. In a mass market, much of this 'industrialized intimacy' is achieved through information systems that track a customer's history and preferences. Examples of companies using information systems in this manner include Ritz-Carlton (Klein et al., 1995), British Airways (Klein and Sasser, 1994) and USAA (Elam and Morrsison, 1993). While this approach works well with a base of repeat customers, it is very difficult to implement 'industrialized intimacy' in anonymous service settings or transient markets where many multinational customer segments coexist. Additionally, a strategy that attempts to give the best service to every customer may be unnecessary and expensive (Rust et al., 1994).

Often, services have some advance cues about the mix of their customer segments. For example, airlines and airports can estimate the mix of nationalities from historic records and national airlines' time of arrivals and departures. Resort areas and theme parks know when certain countries have national holidays or when promotional packages have targeted a 


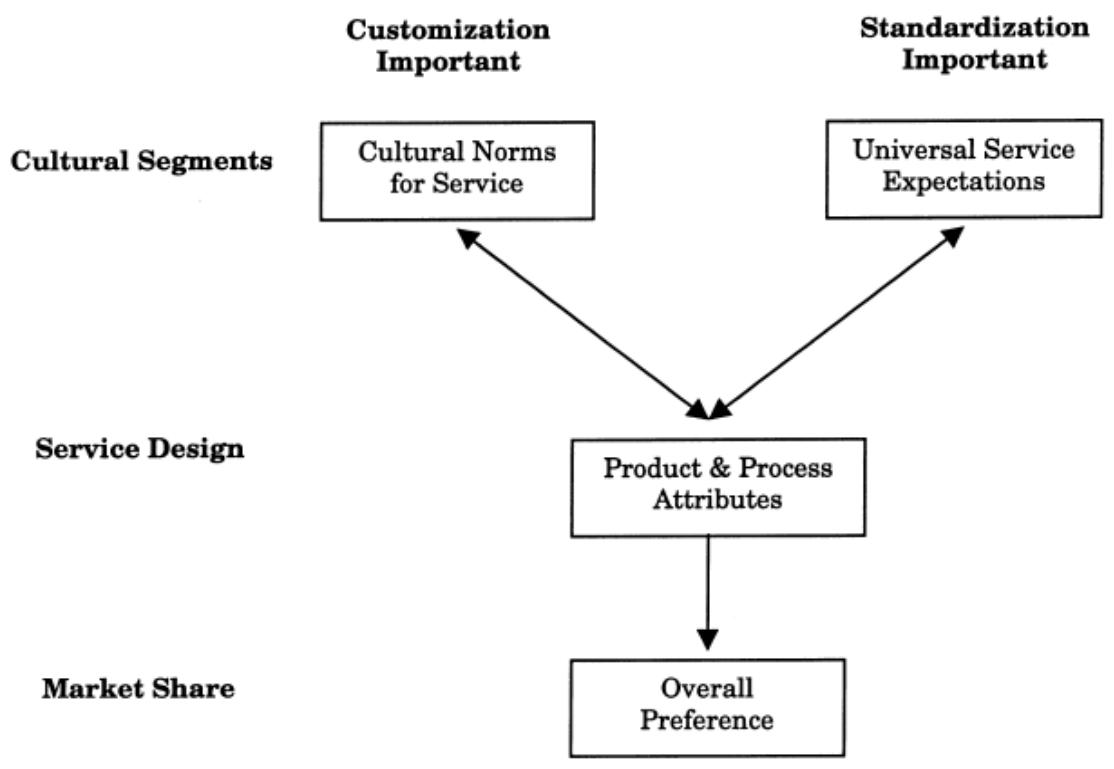

Fig. 1. Conceptual framework for multicultural service design.

national/cultural/religious segment. This information can be used to customize services for these customers during certain time periods or in certain parts of their facilities. An example of this concept would be creating a sub-brand for an important (high yearly revenue per customer) national segment. According to Teare (1993), Hilton hotels implemented an approach that matches the needs of customers from different nationalities to a specially adapted style or area of hotel service. Specifically, they have distinctive service features and special amenities appealing to Japanese clientele. These include Japanese guest service materials, food and beverage offerings and special slippers and bathrobes.

Generally, it appears that some services can be standardized while others are customized to address individual customer needs (Rust et al., 1994). In the next section, we propose a framework to address the level of service customization for multicultural contexts.

\section{Proposed Conceptual Framework}

For our conceptual framework (Fig. 1), we refer to culture-based preferences for certain service attributes as cultural norms for service. Relevant to service design, cultural segments would have distinct cultural norm preferences for service product attributes such as food preparation (e.g. Kosher, vegetarianism, national or regional styles), lodging (e.g. bed styles, room arrangement, or cleanliness) or methods of conveying menu items (e.g. written text, plastic or pictorial food replications, or a kitchen tour). Similarly, segments have different cultural norms for service process attributes such as personal interaction (formality level, personal recognition or personalization) and waiting-line behavior (size, spacing, or queue discipline). This leads us to our first proposition.

Proposition 1. In their evaluation of service designs, cultural segments will prefer service product and process attributes that are in line with their cultural norms. 
On the other hand, customers come to a service with certain expectations not related to their own cultural norms. When foreign customers go to McDonalds, they expect fast, standardized, American-style food. Through various information sources or previous experience, customers have developed service expectations for wait time, food preparation time, employee formality and other design attributes. According to Hofstede's (1980) theory, customers will choose a well-known service over all others to minimize risk in uncertain environments. Also, there are attributes that have universal appeal and importance for all cultures. Attributes such as price and waiting times fall into this category. This leads to the next proposition.

\section{Proposition 2. Cultural segments will share similar preferences for promoted attributes of} service concepts that have universal appeal.

Our conceptual framework shows two opposing forces occurring in Fig. 1. The customization force occurs because a manager must decide which attributes are important to align with each cultural segment's service norms. Often, this decision will require tradeoffs because of practicality issues, costs, potential benefits and public relations. The standardization force occurs because the service firm either manages customer expectations so cultural segments expect a certain experience or determine which attributes have universal appeal. Thus, an appropriate service design attempts to match attribute levels to cultural segments by focusing on and addressing one or both of these forces.

\section{Methodology}

In order to design services and formulate operations strategy for multicultural markets, managers need to determine: (1) important service attributes along with each customer segment's preference model for them, (2) the attributes that are appropriate for standardization for all segments or customization for a specific segment, (3) the practicality and economic feasibility of customizing pertinent attributes and (4) the market share or profit implications of their chosen strategy. In this section, we outline a methodology for evaluating service designs according to our framework and present a detailed case analysis applying the method.

\section{Overview of Discrete Choice Analysis}

A popular method for determining the attribute levels of a new service involves modeling customer preferences in response to experimentally designed service profiles. This approach, commonly known as probabilistic discrete choice analysis (DCA), has been used to model decision-maker's choice processes in a variety of academic disciplines (Louviere and Timmermans, 1990; Pullman and Moore, 1999; Verma and Thompson, 1996).

Discrete choice experiments involve careful designs of service profiles (with specific levels of attributes) and choice sets in which two or more service profiles (alternatives) are offered to decision-makers. Each subject in a DCA experiment typically receives several choice 
sets to evaluate (e.g. 8-32 sets) with two or more hypothetical services to choose from in each set. From each set, the individual chooses one option. The decision-makers' choices (dependent variable) are a function of the attributes of the chosen alternative, personal characteristics of the respondents and unobserved effects captured by a random component.

DCA applications based on choice experiments typically involve the following steps: (1) identification of attributes, (2) specification of attribute levels, (3) experimental design, (4) presentation of alternatives to respondents and (5) estimation of choice model (Verma et al., 1999). A number of past studies have shown that in general, the market share predictions generated from multinomial logit (MNL) or more advanced econometric models (e.g. nested logit) based on DCA are accurate (Ben-Akiva and Lerman, 1991; Green and Krieger, 1996; Louviere and Timmermans, 1990).

DCA is an appropriate tool for developing service designs in markets with multicultural segments for the following reasons. First, it enables researchers to determine if there are significant differences between the segments' preference models. Second, researchers can evaluate changes to each attribute of a specific service design for a segment or concept. Finally, one can look at financial tradeoffs of implementing different service strategies.

\section{Detailed Case Analysis}

We conducted a detailed case analysis of food court operations at one of the busiest US international airport terminals, referred to as Big City International Terminal (BCIT) using the DCA method. Four food service companies are situated in the only food court on the BCIT's departure level. The terminal handles only international flights on non-domestic airlines. The information presented in this article is based on the data collected from the BCIT terminal management, food-service vendors and customer choice data collected during 1998.

We chose to conduct the analysis at BCIT for the following reasons: (1) large concentrations of international people nations visit BCIT, (2) the terminal layout limits the total market of customers to choosing a food-service vendor from a fixed set of alternatives creating an unusual opportunity to characterize the entire market environment, (3) potential customers were actually able to see all the food-service vendors at the same time, therefore it is reasonable to presume that the firm-related issues on which customers focus are marketing (brand name, price, promotion, product) and operational (waiting time, service variety, quality), (4) the flight schedule at BCIT is fixed, therefore the arrival pattern of different customer segments is reasonably predictable and (5) there are a fixed number of food-service vendors with very different yet simplistic food concepts. This simplicity allowed us to experimentally design many different service modifications for each vendor.

\section{Big City International Terminal Food Court}

According to Freathy and O'Connell (1998), the capital required to develop and maintain airports is generated from both aeronautical and commercial sources. Because aeronautical 
revenue has remained static, commercial revenue, particularly revenues derived from airport retailing, has provided significant opportunities for operating authorities. With the exception of duty free shopping, food and beverage operations provide the majority of international terminal revenues. For the food court we examined, the lease payments made to terminal management by a particular vendor are a percent of the vendor's sales. Terminal management would like to determine the appropriate service design for vendors to increase this revenue.

In a multinational setting, food and beverage service design is a challenging problem due to cultural differences in uncertainty avoidance or the way people react to uncertainties and ambiguities inherent in daily living (Hofstede, 1980; Lee and Ulgado, 1997). Generally, international travelers attempt to avoid uncertainty and choose food from their respective cultures or internationally recognized brand names (Jain, 1989; Martenson, 1987; Clark, 1990; Clark et al., 1996). The remainder of this section includes an overview of the respondent demographics and their purchase behavior, the choice behavior market share models for three respondent segments and operational plans for the vendors.

\section{Survey Instrument and Data Collection}

The customer preferences survey was conducted with three segments, those customers flying on Latin American, Japanese and European flights as they represented the majority of the customers at BCIT food service operations. The survey was administered in the food court and waiting areas of the terminal. All questionnaires and interviews were conducted in Spanish, Japanese or English depending on the customer's preference. In this study, primary language and country of origin represents a proxy for culture (Hofstede, 1980).

The first stage involved identification of relevant product/service attributes and their levels. We interviewed 100 randomly selected airline passengers ( 27 Spanish speaking, 23 Japanese speaking and 60 English speaking) to identify the important attributes they used to choose a food vendor. We asked them open-ended questions such as: what did you buy, why did you buy it, why did you chose that food vendor, what else would you purchase if it were available and if you did not purchase then why not? Based on their responses, we identified the five most frequently mentioned attributes according to the approach recommended by Verma et al. (1999) and Griffin and Hauser (1993). These attributes were brand name (i.e. the restaurant is either part of a branded international chain or it sells branded food items), menu variety (i.e. the number of different food items served by a particular restaurant), wait-beforeordering, service time, and price of a standard meal and drink. To overcome communication barriers, managers wanted to consider language-related attributes, so we added menu language and picture display of popular meals.

Next, we identified the relevant levels (possible values) for each of the seven attributes selected for the study. The final attribute levels reflect realistic values and were selected after detailed discussions with BCIT management. For example, brand name was selected as a twolevel attribute (local chain versus national chain) and menu variety was selected as a three-level 
attribute to reflect low, medium and large number of possible choices in a menu. Either two or three-levels were selected for the rest of the attributes. BCIT management was exploring the

\begin{tabular}{|c|c|c|c|c|}
\hline \multirow{2}{*}{$\begin{array}{l}\text { Attributes and levels } \\
\text { (Experimental design code) }\end{array}$} & \multicolumn{4}{|l|}{ Restaurant } \\
\hline & 1 & 2 & 3 & 4 \\
\hline \multicolumn{5}{|l|}{ Brand name } \\
\hline Level $1(-1)$ & Local chain & Local chain & Generic food items & Local chain \\
\hline Level $2(+1)$ & McDonalds & Pizza Hut/Dominos & La Prefreda/Goya & Subway/Boston market \\
\hline \multicolumn{5}{|l|}{ Variety } \\
\hline Level $1(-1)$ & Burger, fries, ice-cream & Pizza & Hot dog, fries, nachos & Sandwich, soup, ice-cream \\
\hline $\begin{array}{l}\text { Level } 2(0) \\
\quad \text { (add to level } 1 \text { items) }\end{array}$ & $\begin{array}{l}\text { + Chicken nuggets and } \\
\text { salads }\end{array}$ & + Lasagna, pasta & + Burritos, tacos & + Udan noodle soup, salads \\
\hline $\begin{array}{l}\text { Level } 3(+1) \text { (add to } \\
\text { level } 1 \text { and } 2 \text { items) }\end{array}$ & $\begin{array}{l}\text { + Special burgers and } \\
\text { sandwiches }\end{array}$ & + Salads, soups & + Tamales, enchiladas & + Sushi, simple Asian dishes \\
\hline \multicolumn{5}{|l|}{ Wait before ordering } \\
\hline Level $1(-1)$ & $0-2 \mathrm{~min}$ & $0-2 \mathrm{~min}$ & $0-2 \min$ & $0-2 \mathrm{~min}$ \\
\hline Level $2(0)$ & $3-4 \mathrm{~min}$ & $3-4 \mathrm{~min}$ & $3-4 \mathrm{~min}$ & $3-4 \mathrm{~min}$ \\
\hline Level $3(+1)$ & $5-6 \mathrm{~min}$ & $5-6 \mathrm{~min}$ & $5-6 \mathrm{~min}$ & $5-6 \mathrm{~min}$ \\
\hline \multicolumn{5}{|l|}{ Service time } \\
\hline Level $1(-1)$ & $0-2 \mathrm{~min}$ & $0-2 \min$ & $0-2 \min$ & $0-2 \min$ \\
\hline Level $2(0)$ & $3-4 \mathrm{~min}$ & $3-4 \mathrm{~min}$ & $3-4 \mathrm{~min}$ & $3-4 \mathrm{~min}$ \\
\hline Level $3(+1)$ & $5-6 \min$ & $5-6 \min$ & $5-6 \mathrm{~min}$ & $5-6 \min$ \\
\hline \multicolumn{5}{|l|}{ Menu language } \\
\hline Level $1(-1)$ & English & English & English & English \\
\hline Level $2(0)$ & + Spanish & + Spanish & + Spanish & + Spanish \\
\hline Level $3(+1)$ & + Japanese & + Japanese & + Japanese & + Japanese \\
\hline \multicolumn{5}{|l|}{ Picture display } \\
\hline Level $1(-1)$ & No & No & No & No \\
\hline Level $2(+1)$ & Yes & Yes & Yes & Yes \\
\hline \multicolumn{5}{|l|}{ Price (\$): meal + drinks } \\
\hline Level $1(-1)$ & 4 & 4 & 4 & 4 \\
\hline Level $2(0)$ & 7 & 7 & 7 & 7 \\
\hline Level $3(+1)$ & 10 & 10 & 10 & 10 \\
\hline
\end{tabular}

Table 1 Attributes and levels

possibility of offering four broad types of restaurants: burger, pizza/Italian, hot dogs/Mexican and deli concept. These are henceforth referred to as burger, pizza, dogs and deli respectively. Table 1 lists the selected attribute levels for each of the four types of restaurants. Note that attribute levels for 'brand name' and 'variety' are different for each of the four service alternatives.

After identifying the attribute and their levels, a fractional factorial design of 18 experimental profiles was used for each restaurant concept in accordance with the Hahn and Shapiro (1966) design catalogue. The profiles contained different levels of each of the seven attributes described above. Each choice set contains one profile for each of the four types of restaurants. As illustrated with the example in Table 2, each respondent was asked to choose one out of the five possible choices (one of the four restaurants or neither) for each choice set. Another part of the survey dealt with respondents' demographic characteristics. Both the preliminary and final questionnaires were originally written in English, translated into Japanese 
and Spanish by two bilinguals and back translated into English by two different bilinguals as per recommended methods (Brislin, 1970; Triandis, 1976). The final survey instrument was administered in the three languages (Japanese, Spanish and English) to approximately 500 travelers, randomly selected from passengers waiting in the food court and other waiting areas before security clearance. All intercepts occurred during June through October 1998, 452 of those questionnaires were usable ( $90 \%$ response).

\begin{tabular}{|c|c|c|c|c|c|}
\hline \multirow[t]{2}{*}{ Choice set \#11 } & \multicolumn{4}{|l|}{ Restaurant } & \multirow[t]{2}{*}{ Neither } \\
\hline & 1 & 2 & 3 & 4 & \\
\hline Brand name & McDonalds & Local restaurant & La Prefreda/Goya products & Subway/Boston market & \\
\hline Variety & $\begin{array}{l}\text { Burger, fries, } \\
\text { ice-cream }\end{array}$ & $\begin{array}{l}\text { Pizza, lasagna, pasta, } \\
\text { salads and soups }\end{array}$ & $\begin{array}{l}\text { Hot dogs, fries, nachos, burritos, } \\
\text { tacos tamales, and enchiladas }\end{array}$ & $\begin{array}{l}\text { Sandwich, soup, ice-cream, } \\
\text { udan noodle soup and salads }\end{array}$ & \\
\hline $\begin{array}{l}\text { Wait time } \\
\text { (before ordering) }\end{array}$ & $5-6 \min$ & $0-2 \mathrm{~min}$ & $3-4 \min$ & $0-2 \min$ & \\
\hline Service time & $0-2 \mathrm{~min}$ & $3-4 \mathrm{~min}$ & $5-6 \min$ & $3-4 \mathrm{~min}$ & \\
\hline Menu language & English & $\begin{array}{l}\text { English, Spanish } \\
\text { and Japanese }\end{array}$ & English and Spanish & English and Spanish & \\
\hline Picture display & Yes & No & No & No & \\
\hline $\begin{array}{l}\text { Price }(\$) \text { : meal }+ \text { drinks } \\
\text { I would purchase } \\
\text { food from }\end{array}$ & 4 & 4 & 10 & 7 & \\
\hline
\end{tabular}

Table 2 A sample choice set

\section{Demographics and Flight Departure Time Information}

While the Japanese speaking respondents were all Japanese nationals departing for Japan, the Spanish speaking respondents were those people who used Spanish as their primary language, resided in Mexico or the US and were departing for Mexico. The English speaking segment resided in the US, UK and Western Europe and were departing for Europe. Henceforth, these segments are referred to as the Japanese, Spanish, and English segments, respectively. All respondents were segmented by both language and national carriers because these attributes have operational implications. Further segmentation (e.g. Swedish versus German versus

Respondents demographic profile

\begin{tabular}{lllllllrr}
\hline & $\begin{array}{l}\text { Wait time in } \\
\text { food court (min) }\end{array}$ & $\begin{array}{l}\text { Cost per eating } \\
\text { person (\$) }\end{array}$ & $\begin{array}{l}\text { Eaters in } \\
\text { party }\end{array}$ & $\begin{array}{l}\text { Age } \\
\text { (yrs) }\end{array}$ & $\begin{array}{l}\text { Gender } \\
\text { (\% male) }\end{array}$ & $\begin{array}{l}\text { Speak } \\
\text { English (\%) }\end{array}$ & $\begin{array}{l}\text { Speak } \\
\text { Spanish (\%) }\end{array}$ & $\begin{array}{l}\text { Speak } \\
\text { Japanese (\%) }\end{array}$ \\
\hline All (452) & 48.17 & 4.51 & 2.55 & 33.88 & 48 & 77 & 34 & 20 \\
English (253) & 51.56 & 5.25 & 2.41 & 35.05 & 46 & 100 & 15 & 3 \\
Spanish (117) & 33.42 & 3.74 & 3.00 & 29.45 & 50 & 66 & 100 & 0 \\
Japanese (82) & 70.87 & 3.02 & 2.41 & 36.80 & 49 & 24 & 0 & 100 \\
\hline
\end{tabular}

${ }^{\text {a }}$ Figures in the brackets represent the number of respondents, $N$.

Table 3 Respondents demographic profile

British) would not be meaningful to BCIT management because there are many different Europeans and US citizens aggregated during a certain departure window. By comparing the segment's choice models, one can determine if this segmentation is appropriate.

Several differences exist between the segments. Table 3 shows the demographic profile of the respondents. The English segment spent the most money per person while the Japanese 
spent the least. The Spanish segment spent below average per person but bought food for more people than the other two segments. The Japanese segment spent the most time waiting in the food court while the Spanish segment spent the least.

Most respondents departure times fell between 4 and 8 PM (40\%), followed by 8 AM12 PM (29\%) and 8-12 AM (24\%). The Spanish segment generally departed between 8 PM-12 AM (59\%) and 8 AM-12 PM (30\%) while the majority of the Japanese segment departed between 8 AM-12 PM (97\%).

\section{Customer Choice Models}

We used the NTELOGIT program by Intelligent Marketing Systems (1992) to estimate MNL choice models for all respondents. NTELOGIT uses maximum likelihood estimation to generate relative weights ( $\beta$ in Eq. (A.2), known as part-worth utilities - see Appendix A) for each service attribute. The parameters _ are similar to ordinary least squares regression coefficients - except that the dependent variable (probability of selection) is related to the independent variables according to Eqs. (A.1) and (A.2) specified in Appendix A.

The MNL models were developed for each segment (English, Spanish and Japanese) as shown in Table 4. One can look at the relative size of the intercept to get a general idea of how the segment felt about the restaurant concept (burger, pizza, dogs and deli). To interpret the attribute information, we first look at the possible values that an attribute can have and multiply a possible value (experimental design code from Table 1) by its corresponding weight. We then sum these products over all the attributes and the resulting sum is the overall preference that the segment has for a competitor. Higher preference values mean higher probability that customers will prefer a service alternative (Verma et al., 1999).

In addition to the $\beta$ parameters for each attribute, Table 4 also presents summary goodness-of-fit statistics for the three MNL models. The McFadden's $\rho^{2}$ and adjusted $\rho^{2}$ values are similar to $R^{2}$ and adjusted $R^{2}$ in ordinary least squares regression and therefore demonstrate the 'fit' between the estimated model and observed empirical data (Ben-Akiva and Lerman, 1991). As shown in Table 4 , the adjusted $\rho^{2}$ values are very high $(0.67,0.71,0.63)$ for each of the three models thus the estimated MNL models fit the empirical data very well.

In these MNL models, $\beta$ values are specific to each alternative. For example, we explicitly estimate the impact of brand names, a measure of perceived quality or brand equity for the four types of food-service operations at BCIT. Similarly the attribute 'variety' does not mean the exact same menu items for all the competitors and hence alternative-specific 13 weights are necessary.

\section{English Model Interpretation}

Interpreting the model for the English segment, we saw several important trends. Large positive 'intercept' values for the deli and pizza concepts indicated that they are most popular. 


\begin{tabular}{|c|c|c|c|}
\hline Variables & English & Spanish & Japanese \\
\hline \multicolumn{4}{|l|}{ Intercepts } \\
\hline Burger & $0.70^{*}$ & $2.15^{*}$ & $1.08^{*}$ \\
\hline Pizza & $0.86^{*}$ & $1.56^{*}$ & $0.29^{*}$ \\
\hline Dogs & $0.22^{*}$ & $1.23^{*}$ & $-0.40^{*}$ \\
\hline Deli & $1.27^{*}$ & $1.48^{*}$ & $1.12^{*}$ \\
\hline \multicolumn{4}{|l|}{ Brand name } \\
\hline Burger & -0.09 & -0.11 & -0.12 \\
\hline Pizza & $0.12^{*}$ & -0.11 & 0.07 \\
\hline Dogs & $-0.21^{*}$ & $-0.39^{*}$ & 0.10 \\
\hline Deli & $-0.13^{*}$ & $0.17^{*}$ & -0.03 \\
\hline \multicolumn{4}{|l|}{ Variety } \\
\hline Burger & $0.27^{*}$ & 0.11 & $0.23^{*}$ \\
\hline Pizza & $0.14^{*}$ & 0.10 & 0.11 \\
\hline Dogs & 0.07 & $0.34^{*}$ & $-0.40^{*}$ \\
\hline Deli & 0.04 & -0.06 & $0.43^{*}$ \\
\hline \multicolumn{4}{|l|}{ Wait to order } \\
\hline Burger & $-0.18^{*}$ & $-0.74^{*}$ & $-0.15^{*}$ \\
\hline Pizza & $-0.22^{*}$ & -0.11 & -0.08 \\
\hline Dogs & $-0.31^{*}$ & 0.19 & 0.01 \\
\hline Deli & 0.06 & 0.10 & 0.01 \\
\hline \multicolumn{4}{|l|}{ Service wait } \\
\hline Burger & $-0.25^{*}$ & -0.08 & -0.12 \\
\hline Pizza & -0.03 & 0.03 & -0.09 \\
\hline Dogs & $0.13^{*}$ & $-0.20^{*}$ & $-0.16^{*}$ \\
\hline Deli & $-0.11^{*}$ & -0.09 & -0.11 \\
\hline \multicolumn{4}{|l|}{ Menu language } \\
\hline Burger & $-0.48^{*}$ & $-0.87^{*}$ & $-1.01^{*}$ \\
\hline Pizza & $-0.56^{*}$ & $-0.91^{*}$ & $-0.83^{*}$ \\
\hline Dogs & $-0.83^{*}$ & $-1.15^{*}$ & $-0.98^{*}$ \\
\hline Deli & $-0.48^{*}$ & $-0.74^{*}$ & $-0.78^{*}$ \\
\hline \multicolumn{4}{|l|}{ Price (\$): meal + drinks } \\
\hline Burger & 0.10 & $0.32^{*}$ & $0.21^{*}$ \\
\hline Pizza & -0.04 & 0.15 & -0.04 \\
\hline Dogs & 0.10 & $0.32^{*}$ & $0.27^{*}$ \\
\hline Deli & -0.07 & $0.28^{*}$ & $0.18^{*}$ \\
\hline \multicolumn{4}{|c|}{ Picture display of popular items } \\
\hline Burger & $0.11^{*}$ & -0.11 & $0.17^{*}$ \\
\hline Pizza & -0.01 & -0.06 & 0.03 \\
\hline Dogs & 0.03 & $-0.22^{*}$ & $0.24^{*}$ \\
\hline Deli & 0.07 & $0.17^{*}$ & 0.06 \\
\hline \multicolumn{4}{|l|}{ Goodness-of-fit statistics } \\
\hline McFadden's $\rho^{2}$ & 0.71 & 0.75 & 0.69 \\
\hline Adjusted McFadden's $\rho^{2}$ & 0.67 & 0.71 & 0.63 \\
\hline
\end{tabular}

Table 4 Estimated MNL choice models

* Statistically significant at the $5 \%$ level.

The brand names, La Prefreda/Goya (dogs) and Subway/Boston market (deli) were perceived negatively, Pizza Hut/Dominoes (pizza) was favorably perceived. Preference increased as the variety increased at burger (special burgers and sandwiches) and pizza (pasta, salad and soups). Shorter wait and service times at burger and pizza increased preference. Dogs' wait-to-order 
time was perceived negatively but longer service times were viewed favorably. Deli's service time wait was perceived negatively but not the wait to order. The group preferred an English menu but preference decreased greatly with language additions. Pictures were not preferred for burger and pizza but were preferred for dogs and deli. Price had no significant impact on preference.

\begin{tabular}{lc}
\hline Model & Log-likelihood score \\
\hline Testing English and Spanish models & -218.72 \\
English model $(\mu=1.0)$ & -190.17 \\
Spanish model $(\mu=1.0)$ & -594.28 \\
Joint model with optimum varying scale $(\mu$ for English model $=1.0)$ and $(\mu$ for Spanish model $=1.495)$ & $370.80^{*}$ \\
$\chi^{2}$-statistic (d.f. $\left.=33\right)$ & -218.72 \\
Testing English and Japanese models & -172.27 \\
English model $(\mu=1.0)$ & -471.69 \\
Spanish model $(\mu=1.0)$ & $161.42^{*}$ \\
Joint model with optimum varying scale $(\mu$ for English model $=1.0)$ and $(\mu$ for Spanish model $=1.377)$ & \\
$\chi^{2}$-statistic (d.f. $\left.=33\right)$ &
\end{tabular}

${ }^{*}$ Statistically significant at the $5 \%$ level.

Table 5 Swait-Louviere $\chi^{2}$ - test for equality of parameters.

\section{Spanish Model Interpretation}

In terms of restaurant concepts, burger was by far the most popular for the Spanish group. But only the deli brand names have a positive impact on preference for the vendor. The increase in variety at dogs (more Mexican food items) was positively perceived. Preference decreased with increased order waiting time at burger and service time at dogs. Adding menu languages decreased preference. Pictures of the food are viewed favorably for the deli concept. The group was not price sensitive.

\section{Japanese Model Interpretation}

The burger and deli were the most popular concepts for the Japanese group. Brand names had no significant impact. Increasing variety was not favorable at dogs (an increase in hispanic food items) but was favorable for burger and deli (an increase in Asian food items). Preference decreased with increased order wait at burger or service wait at dogs. while multilingual menus were undesirable, food pictures were preferred. The group was not price sensitive.

\section{Cultural Segment Preference Commonalties and Difference}

Although, it is possible to identify the general preferences trends for MNL choice models, it is not appropriate to directly compare the $\beta$ coefficients for two models (see Appendix A). The recommended statistical test for equality of MNL model parameters is based on a $\chi^{2}$-statistic developed by Swait and Louviere (1993). Based on the results of the Swait and Louviere $\chi^{2}$-test we formally conclude that overall, the parameters for both the Spanish and Japanese models are different from the English model at the $5 \%$ level. The test results are presented in Table 5 and the associated statistical information is again included in Appendix A. 
In Table 6, we have summarized the preference differences and similarities between groups. When differences exist, in the third column we show the customization implications for management.

\section{Differences}

There are several attributes where the cultural segments' preferences differed. The segments lacked agreement on branding, variety and picture display. Additionally, the different groups were sensitive to the two waits depending on the vendor. The English group was generally more wait sensitive and preferences for dogs depended greatly on the waits. In most cases, the differences can be accommodated by scheduling adequate amounts of people during the English group time slot or adding variety for Spanish or Japanese customers during their time slots.

\begin{tabular}{|c|c|c|c|}
\hline Attribute & Differences & Similarities & Customization implications \\
\hline \multicolumn{4}{|l|}{ Product } \\
\hline Brand & Generally mixed about brands & $\begin{array}{l}\text { No significant preference for } \\
\text { McDonalds }\end{array}$ & Difficult \\
\hline Variety & $\begin{array}{l}\text { Japanese want Asian and burger } \\
\text { variety not Mexican food, Spanish } \\
\text { want Mexican food and English } \\
\text { want more burgers and Italian food }\end{array}$ & Increase variety & $\begin{array}{l}\text { Add Mexican food during PM, add } \\
\text { Japanese food during AM and } \\
\text { increase variety at other vendors }\end{array}$ \\
\hline Menu language & None & No additional languages preferred & No need to customize \\
\hline Price & None significant & Not sensitive to pricing & No need to customize \\
\hline Picture display & $\begin{array}{l}\text { Japanese prefer pictures for all, } \\
\text { Spanish want pictures for deli }\end{array}$ & Preference for pictures at deli & $\begin{array}{l}\text { Add pictures during the appropriate } \\
\text { time slots }\end{array}$ \\
\hline \multicolumn{4}{|l|}{ Process } \\
\hline Wait to order & $\begin{array}{l}\text { English want reduced waits at most } \\
\text { locations }\end{array}$ & $\begin{array}{l}\text { Wait sensitive at Burger, wait } \\
\text { insignificant at deli }\end{array}$ & $\begin{array}{l}\text { Schedule extra counter personnel } \\
\text { for appropriate time slots }\end{array}$ \\
\hline Service time & $\begin{array}{l}\text { English are wait sensitive at burger } \\
\text { and deli, Japanese and Spanish are } \\
\text { wait sensitive for dogs }\end{array}$ & $\begin{array}{l}\text { No significant wait sensitivity for } \\
\text { pizza }\end{array}$ & $\begin{array}{l}\text { Schedule extra kitchen personnel } \\
\text { for appropriate time slots }\end{array}$ \\
\hline
\end{tabular}

Table 6 Group similarities and differences.

\section{$\underline{\text { Similarities }}$}

Notably, all groups tended to have no significant preference for burger brand names, did not want menus in other languages, were order wait sensitive at burger but not service wait sensitive at pizza and generally preferred more variety.

\section{Support for Propositions}

To support Proposition 1, we would expect to see differences that relate to cultural norms in variety, food pictures and menu languages. Generally each segment preferred a variety extension that matched their cultural norm. Additionally, the Japanese segment preferred food pictures in most contexts (pictorial and plastic food displays are a cultural norm in Japan), the Spanish segment wanted to see Asian but not Mexican food items. While none of the segments wanted menus in their own language, this could be explained by the simplicity of the service concept with most food items in view of the customers. 
To support Proposition 2, the attributes for waits, known brands and pricing should show the same preference direction for all segments. In almost all statistically significant cases, any wait time decreased preference. But, increased service wait actually increased preference for the English group at dogs. Burger had the only universally known brand name but in this case the preference was not statistically significant. Price was either insignificant or did not adversely affect vendor choice by any group. Thus, we would conclude that Proposition 2 was weakly supported.

\section{Impact of Operations Strategy on Market Performance and Suggested Strategy Changes}

Given the above models for each segment, we next look at what each vendor can do to improve their market share. The food court market was determined by converting customer traffic estimates from BCIT schedules into forecasts for food court customers. We assume that this market is made up of English (60\%), Spanish (25\%) and Japanese (15\%) customers. According to our models and the actual sales data, the burger concept receives most of the Japanese and Spanish market share. The burger concept was an internationally recognized brand name and had more sales volume than the three local vendors together. BCIT was most concerned with improving the sales performance of the local vendors. Thus, in the following analysis, we have left burger's attributes at its existing levels and changed each vendor in isolation of the other vendors. In a zero sum game, we then set each local vendor at its maximum market share configuration (Eq. (A.1) from Appendix A) and look at the overall impact.

\begin{tabular}{lll}
\hline Pizza & Dogs & Deli \\
\hline Local branding & Local branding & Local branding \\
Increase to high variety & Increase to high variety & Increase to high variety \\
Improve order waits to $0-2 \mathrm{~min}$ & Improve order waits to $0-2 \mathrm{~min}$ & Maintain/increase order waits to $5-6 \mathrm{~min}$ \\
Reduce preparation time to $0-2 \mathrm{~min}$ & Maintain existing preparation time & Reduce preparation time to $0-2 \mathrm{~min}$ \\
English only menu & English only menu & English only menu \\
No pictures & Keep picture displays & Add picture displays \\
Increase average price & Increase average price & Increase average price \\
Share change: $+9.72 \%$ & Share change: $+9.53 \%$ & Share change: $+13.70 \%$ \\
\hline
\end{tabular}

Table 7 Suggested strategy changes for current competitors and corresponding maximum market share impact.

Table 7 shows each vendor's market share maximizing changes. If all vendors take on market share maximizing attributes simultaneously, the overall impact is shown in Table 8. For example, if pizza made market share maximizing changes without competitors retaliating, it would gain $9.7 \%$ market share, if all competitors made market share maximizing changes then pizza only gains $1.8 \%$. The biggest positive changes to pizza come from increasing the variety to include pastas and salads and reducing the overall wait time (to order and deliver food). Pizza gains share from the English and Spanish segments but loses share from the Japanese segment.

Similarly, the biggest positive changes to dogs come from increasing the variety to include more Mexican food items and reducing the wait time to order. Here dogs share gains 
$9.53 \%$, acting alone and $2.57 \%$, if all change. These changes are reflected positively with a large shift from the Spanish segment followed by the English segment. These changes are negative for the Japanese segment but overall the new concept gains market share.

Finally for deli, increased variety (more Asian style foods), reduced waiting time for service, and added pictures of food contribute to the largest market share improvements (6.25\% overall when all vendors change). By adding specialty Asian foods and picture displays, the deli gains a large portion of the Japanese segment. These additions are also viewed favorably by the other two segments.

\section{Implementation of Operational Changes}

For this particular context, there are several ways that vendors could customize their service for different segments. Because there was very little overlap between segment groups during the day, process attributes (e.g. reduced service time) could be adjusted by adding staff during time sensitive time slots, product attributes (e.g. increased variety) could also be adjusted during time slots. For example, it would appear that the Japanese segment spent the most time in the food court but spent the least per capita (Table 3). The Spanish segment spent the least time in the food court, spent below average amounts on each person and purchased food for a bigger party. Thus, there was an opportunity to increase sales to each of these segments. In this competitive environment, it made sense for some vendors to customize their

\begin{tabular}{llrrr}
\hline & Weights (\%) & Pizza & Dogs & Deli \\
\hline Overall market share change (\%) & & 1.80 & 2.57 & 6.25 \\
English speaking customers (\%) & 60 & 2.69 & 3.78 & 1.30 \\
Spanish speaking customers (\%) & 25 & 1.35 & 7.56 & 3.24 \\
Japanese speaking customers (\%) & 15 & -0.99 & -10.58 & 31.09 \\
\hline
\end{tabular}

Table 8 Market share changes by group with simultaneous implementation

food offerings for these customer segments. while a variety increase may appear to add to the service delivery complexity, vendors could take advantage of the departure time windows. The majority of the Japanese and Spanish segments use the food court from 8 AM to 12PM and 8 $\mathrm{PM}$ to $12 \mathrm{AM}$, respectively. Thus, management could modify the menu for those hours of the day only, both off-peak times.

Based on the results of this study, the BCIT authority planned to implement the suggested improvements in several phases. The first phase was the modification of dogs, adding Mexican food items to the menu at night from 8 PM to 12 AM and reducing the waiting times by improving process and labor scheduling efficiencies. The increase in menu items added additional complexity to the process but the potential payoff would significantly outweigh the problems. At the time of this report, the modifications had been in effect for 3 months. During this period, the vendor increased sales by $50 \%$ from the previous year (with a similar number of passenger departures at the terminal). While this study assumed a zero sum game by shifting share among the existing four vendors, we did not estimate the effects of drawing new 
customers from the population that were previously non-purchasers. This phenomenon explains why current sales greatly exceeded our market share projections. In this case, it appears that maximizing market share is a worthy objective for each food court vendor given its substantial effect of attracting new customers.

\section{Discussion}

A firm delivering a service to multicultural markets must decide if it is worth trying to pursue strategies that customize its service product and process attributes for the various cultural segments, or pursue a standardization strategy that is acceptable across segments. We suggested two propositions and a methodology for evaluating service design strategy in this market, we illustrate the use of the method in an actual case and the propositions were generally supported. From this work, we see implications for other services, limitations from this study and ideas for future work.

\section{Implications for Service Operations}

The results of this study have implications for other types of services. To successfully develop strategies in multicultural environments, managers must be sensitive to the similarities and differences the segments have regarding preferences for service product and process attributes. However, process attributes usually involve intangible activities, as such these attributes can be very difficult to customize for different segments. Thus, the option of standardizing a process and managing customer expectations might be more appropriate. On the other hand, firms need to be very careful to address customization of certain important product attributes that could be order winners such as offering kosher food or alcoholic beverages to certain segments.

We could generally confirm that segments have certain different preferences and that attribute preferences converge for certain universal or well-known service's attributes. This result implies that the smaller local services can compete against well-known franchises by catering to the cultural norms of specific segments. But the addition of special foods and other tangible items creates a challenge for managers who are trying to present a uniform brand or service package identity. For example, how do people interpret a hot dog stand that now also serves Mexican food items? In certain service environments, this question would need to be evaluated carefully so as not to dilute a brand's image.

\section{$\underline{\text { Limitations }}$}

The BCIT case examined a specific service context, a high customer contact environment with a strict delivery window due to the short time available before the departure of a flight. Because of this limited context, the results of this study should be viewed with caution when generalizing to other services. One would expect that customers in this context are uniformly more wait time sensitive and less price sensitive. While the particular sample group in this simple service context did not need language support, certainly this would not be the case in 
other settings. Similarly, while branding effects showed mixed results in this context, branding can be a very important quality proxy for many services.

In this study, we used language and national carrier to operationalize culture. While this segmentation had meaningful implications for management, these indicators might be weak proxies for culture in some other environments. Even in the BCIT case, the English speaking segment was actually a European segment thus we would expect a large variation of preferences within the group.

\section{Future Work}

We considered the market share impacts of catering to different national segments in a specific service setting. Future research is needed in determining the cost and benefits of customizing certain portions of a service versus a standardized service offering. From a profit maximizing perspective, certain segments generate more revenue than other segments and it may add too much complexity and cost for a firm if all customers are pleased simultaneously.

While this study examined food and beverage service, there are many other service industries that potentially face diverse national customer segments. Examples of these are international airline flights, off-shore customer service centers, electronic commerce, theme parks and destination resorts and cruise ships. Future research should look at the implications for different service types.

To summarize, we have presented an approach for positioning a service and formulating service strategy in a multicultural environment. The case analysis at $\mathrm{BCIT}$ food-service operations demonstrates the value of DCA and market utility models for service strategy development. Given the calls for multi-functional research from the editors of the major journals, we hope that other research teams will undertake similar projects to analyze interdisciplinary issues related to service strategy formulation.

\section{Appendix A. Discrete Choice Analysis: Background Information}

Discrete Choice Analysis (DCA) is a systematic approach for identifying the relative weights of attributes when a decision maker (e.g. a customer or a manager) chooses an alternative from a set of possible choices. The following section summarizes the main ideas behind the approach. For detailed reviews of DCA see (Gensch and Recker, 1979; Hensher and Johnson, 1980; McFadden, 1986; Louviere and Timmermans, 1990; Swait and Louviere, 1993; Ben-Akiva and Lerman, 1991). Past research shows that after acquiring information and learning about the possible alternatives, consumers define a set of determinant attributes to use to compare and evaluate alternatives. After comparing available alternatives with respect to each of the alternatives, the decision-maker eliminates some alternatives and develops a final choice set $(\mathrm{Cn})$ containing $n$ alternatives. The decision-maker then forms impressions of the various alternatives' positions on the determinant attributes, make value judgments and combine information to form overall impressions of the alternatives. In forming their overall 
impressions, they have to make tradeoffs between the alternatives' different attributes. The above formulation of a decision-maker's choice process is based on the random utility theory (RUT) and on information integration theory (IIT) (Anderson, 1981; Anderson, 1982; Ben-Akiva and Lerman, 1991; Louviere, 1988; McFadden, 1986). Random utility theory assumes that individuals' choice behavior is generated by maximization of preferences or Utility. Louviere (1988) defines utility as 'judgments, impressions or evaluations that decision makers form of products or services, taking all the determinant attribute information into account'.

It has been shown that the choice process briefly described above can be formulated as a MNL model (Ben-Akiva and Lerman, 1991). The MNL model is expressed as

$$
\left(P_{j} \mid C_{n}\right)=\frac{e^{V_{j} \mu}}{\sum_{k=1}^{n} e^{V_{k} \mu}}
$$

where $V_{j}$ represents the systematic component of utility $\left(U_{j}\right)$ of alternative $j$. The model assumes that the utilities $\left(U_{j}\right)$ are comprised of a systematic component $\left(V_{j}\right)$ which can be estimated, and random error $(\varepsilon)$ which is independent and identically distributed according to a Gumbel distribution with a scale parameter $\mu . P_{j} \mid C_{n}$ represents the probability of selecting an alternative and therefore the expected market share. Representing a product or service as a bundle of its attributes and by assuming an additive utility function, an alternative's systematic utility can be calculated as

$$
V_{j}=\sum_{a \in A} \beta_{a} X_{a j}
$$

where $\beta_{a}$ is the relative utility (part-worth utility) associated with attribute $a$.

There are a number of general approaches to finding the $\beta_{a}$ parameters, in practice, however, the maximum likelihood estimation procedure is used (Ben-Akiva and Lerman, 1991). A maximum likelihood estimator is the value of the $\beta_{a}$ parameters for which the observed sample is most likely to have occurred. If $M$ subjects are asked to choose among $n$ alternatives from $K$ distinct choice sets, then the likelihood function, $\mathcal{L}$ is represented as

$$
\mathcal{L}=\prod_{m=1}^{M} \prod_{k=1}^{K} \prod_{j=1}^{n} P_{j k}^{Y_{j k m}}
$$

where $P_{j k}$ represents the probability of the decision maker selecting alternative $j$ in the $k$ th choice set, $Y_{j k m}=1$ if subject $m$ chooses alternative $j$ in choice set $k, Y_{j k m}=0$ otherwise.

Several individual level goodness-of-fit statistics can be calculated for an MNL model. A log-likelihood ratio test is based on the differences between the natural logarithm of the likelihood function (Eq. (A.3)) under two conditions. First, the likelihood ratio is calculated by assuming an equal probability of choosing any alternative in a choice set or by assuming all $\beta_{a}$ parameters to be zero. This natural logarithm of the likelihood (log-likelihood) value is 
represented as $\mathcal{L} \mathcal{L}(0)$. Next, the likelihood ratio is calculated again, assuming the estimated $\beta_{a}$ parameters. This log-likelihood value is called $\mathcal{L L}(\beta)$. Then, the log-likelihood ratio test is defined as

$$
-2[\mathcal{L L}(0)-\mathcal{L} \mathcal{L}(\beta)]
$$

which is $\chi^{2}$-distributed with the degrees of freedom equal to the number of $\beta_{a}$ parameters. McFadden's $\rho^{2}$ and adjusted McFadden's $\rho^{2}$ measures (similar to the $R^{2}$ and adjusted $R^{2}$ in ordinary least squares regression) are defined in the following manner

$$
\rho^{2}=1-\left[\frac{\mathcal{L} \mathcal{L}(\beta)}{\mathcal{L} \mathcal{L}(0)}\right]
$$

adjusted $\rho^{2}$

$$
=1-\left[\frac{\mathcal{L L}(\beta)-\text { number of } \beta_{a} \text { parameters }}{\mathcal{L} \mathcal{L}(0)}\right]
$$

where $0 \leq \rho^{2} \leq 1$ and that $0 \leq$ adjusted $\rho^{2} \leq 1$.

To test if two MNL models contain similar parameters, Swait and Louviere (1993) $\chi^{2}$ test can be used. A direct comparison of $\beta$ parameters for two MNL models is inappropriate because the models contain an imbedded Gumbel scale parameter ( $\mu$ - see Eq. (A.1)) which may not be same for the two models. Appropriate statistical procedure for comparing two MNL models is a $\chi^{2}$-test procedure developed by Swait and Louviere (1993). This procedure first identifies the optimum relative Gumbel scale for the second model and then compares the two models using the following $\chi^{2}$-statistic with $\mathcal{L}+1$ degrees of freedom $(\mathcal{L}$ is the number of attributes)

$$
-2\left[\mathcal{L L}_{\mu}-\left(\mathcal{L} \mathcal{L}_{1}+\mathcal{L} \mathcal{L}_{2}\right)\right]
$$

where $\mathcal{L} \mathcal{L}_{1}$ and $\mathcal{L} \mathcal{L}_{2}$ are the log-likelihood values of the two MNL models without any rescaling and $\mathcal{L} \mathcal{L}_{\mu}$ is the log-likelihood value for the joint model with a rescaling parameter $\mu$.

\section{References}

Anderson, N.H., 1981. Foundations of Information Integration Theory. Academic Press, New York.

Anderson, N.H., 1982. Methods of Information Integration Theory. Academic Press, New York.

Ben-Akiva, M., Lerman, S.R., 1991. Discrete Choice Analysis. MIT Press, Cambridge, MA.

Brislin, R.W., 1970. Back translation for cross-cultural research. Journal of Cross-Cultural Psychology 1, 185-216.

Clark, T., 1990. International marketing and national character: a review and proposal for an integrative theory. Journal of Marketing 54 (4), 66-79. 
Clark, T., Rajaratnam, D., Smith, T., 1996. Toward a theory of international services: marketing intangibles in a world of nations. Journal of International Marketing 4 (2), 9-28.

Danaher, P.J., 1998. Customer heterogeneity in service management. Journal of Service Research 1 (2), 129-139.

Donthu, N., Yoo, B., 1998. Cultural influence on service quality expectations. Journal of Service Research 1 (2), 178-186.

Elam, J., Morrsison, J., 1993. United Services Automobile Association. Harvard Business School Case 9-188-102.

Freathy, P., O'Connell, F., 1998. Supply chain relationships within airport retailing. International Journal of Physical Distribution and Logistics Management 28 (6), 451-462.

Gensch, D.H., Recker, W.W., 1979. The multinomial, multiattribute logit choice model. Journal of Marketing Research 16 (2), 124-132.

Green, P.E., Krieger, A.M., 1996. Individualized hybrid models for conjoint analysis. Management Science 42 (6), 850-867.

Griffin, A., Hauser, J.R., 1993. The voice of the customer. Marketing Science 12 (1,winter), 1-27.

Hahn, G.J., Shapiro, S.S. 1966. A Catalog and Computer Program for the Design and Analysis of Orthogonal Symmetric and Asymmetric Fractional Factorial Experiments. Technical Report Number 66-C 165, Schenectady, NY.

Hensher, D.A., Johnson, L., 1980. Applied Discrete Choice Modeling. Croom-Helin, London.

Heskett, J.L., 1987. Lessons in the service sector. Harvard Business Review 2, 118-126.

Hofstede, G., 1980. Culture's Consequences. Sage Publications, Beverly Hills, CA.

IMS (1992). Intelligent Marketing Systems, Software and User's Manual, Version INTELOGIT. Edmonton, Canada.

Jain, S.C., 1989. Standardization of international marketing strategy: some research hypotheses. Journal of Marketing 53 (1), 70-79.

Klein, N., Sasser, W.E., 1994. British Airways: Using Information Systems to Better Service the Customer. Harvard Business School Case 9-395-065.

Klein, N., Sasser, W.E., Jones, T.O., 1995. The Ritz Carlton: Using Information Systems to Better Service the Customer. Harvard Business School Case 9-395-064.

Kolesar, P., Van Ryzin, G., Cutler, W., 1998. Creating customer value through industrialized intimacy, strategy. Strategy and Business 12, 33-43. 
Lee, M., Ulgado, F., 1997. Consumer evaluations of fast-food services: a cross-national comparison. Journal of Services Marketing 11 (1), 39-52.

Louviere, J., Timmermans, H., 1990. Stated preference and choice models applied to recreation research: a review. Leisure Sciences 12, 9-32.

Louviere, J.J., 1988. Analyzing Decision Making: Metric Conjoint Analysis. Sage Publications, Newbury Park, CA.

Lovemen, G. 1993. Euro Disney: The first 100 days Teaching Note 5-693-082. Harvard Business School, Boston.

Martenson, R., 1987. Is standardization of marketing feasible in culture-bound industries: a European case study. International Marketing Review 4 (3), 7-17.

Mathe, H., Perras, C., 1994. Successful global strategies for service companies. Long Range Planning 27 (2), 36-49.

Mattila, A.S., 1999. The role of culture in the service evaluation process. Journal of Service Research 1 (3), 250-261.

McFadden, D., 1986. The choice theory approach to market research. Marketing Science 5 (4), 275-297.

Parasuraman, A., Zeithaml, V.A., Berry, L.L., 1985. A conceptual model of service quality and its implications for future research. Journal of Marketing 49, 41-50.

Parasuraman, A., Zeithami, V.A., Berry, L., 1988. SERVQUAL: A multiple-item scale for measuring consumer perceptions of quality. Journal of Retailing 64 (1), 12-40.

Pullman, M., Moore, W., 1999. Optimal service design: integrating marketing and operations perspectives. International Journal of Service Industry Management 10 (2), 239-260.

Rust, R.T., Zahorik, A.J., Keiningham, T.L., 1994. Return on Quality. Probus, Chicago.

Swait, J., Louviere, J.J., 1993. The role of scale parameter in the estimation and comparison of multinomial logit models. Journal of Marketing Research 30, 305-314.

Teare, R., 1993. Designing a contemporary hotel service culture. International Journal of Service Industry Management 4 (2), 63-73.

Triandis, H.C., 1976. Methodological problems of comparative research, International Journal of Psychology 11(3).

Verma, R., Thompson, G.M., 1996. Basing service management on customer determinants: the importance of hot pizza. Cornell Hotel and Restaurant Administration Quarterly 37 (3), 18-23. 
Verma, R., Thompson, G.M., Louviere, J.J., 1999. Configuring service operations in accordance with customer needs and preferences. Journal of Service Research 1 (3), 262-274.

Webster, C., 1989. Can consumers be segmented on the basis of their service quality expectations? Journal of Services Marketing 3(2). 